cardiologists to investigate its possibility and, if confirmed, help avoid an unnecessary reoperation or other inappropriate therapy.

\section{REFERENCES}

1. Tallano JV, Gardin JM. Vegetation, tumor, masses \& thrombi. In: Tallano JV, Gardin JM, editors. Textbook of two-dimensional echocardiography. New York: Grune \& Stratton, 1993:239-70.

2. Slavik Z, Salmon AP, Lamb RIC. Unusual left atrial mass following cardiac surgery in an infant. Eur J Cardiothorac Surg 1994;8:566-7.
3. Mera F, Patt J, Israel W, Dubin JD. Atrial septal aneurysm simulating a left atrial mass diagnosed by transesophageal echocardiography. Am Heart J 1993;126:1224-5.

4. Manning WJ, Waksmonski CA, Riley MF. Remnant of the common pulmonary vein mistaken for a left atrial mass: clarification by transoesophageal echocardiography. $\mathrm{Br}$ Heart J 1992;68:4-5.

5. Movsowitz HD, Jacobs LE, Movsowitz C, Kotler MN. Transesophageal echocardiographic evaluation of a transthoracic echocardiographic pitfall: a diaphragmatic hernia mimicking a left atrial mass. J Am Soc Echocardiogr 1993;6:104-6.

\title{
GIANT ATHEROSCLEROTIC ANEURYSM OF THE SINOATRIAL NODAL ARTERY
}

\author{
Sung Ho Kim, MD, ${ }^{\mathrm{a}}$ In Seok Jang, MD, ${ }^{\mathrm{a}}$ Chang Dae Ouck, MD, ${ }^{\mathrm{a}}$ Chong Woo Kim, MD, ${ }^{\mathrm{a}}$ Jun Young Choi, MD, \\ Hyung-Jin Kim, MD, ${ }^{b}$ and Bonggwan Seo, MD, ${ }^{c}$ Chinju, South Korea
}

Aneurysms of the right coronary artery (RCA) are rare and occur most frequently in proximal or midportions of the artery. We report a case of giant atherosclerotic aneurysm of the sinoatrial (SA) nodal artery causing vena caval syndrome, which was treated successfully by surgery. We believe that it is the first case of an aneurysm arising from one of the branches of the RCA.

A 61-year-old woman was referred to our hospital with the diagnosis of right atrial mass in January 1996. She had a 2-month history of shortness of breath on exertion and of slowly progressing facial edema. On physical examination, the patient had facial edema, engorgement of neck veins, engorgement of veins on the chest wall, and a liver palpable by a breadth of four fingers. Findings on the electrocardiogram were within normal limits. A chest roentgenogram showed a huge mass obliterating the right cardiac border. Chest computed tomography (CT) demonstrated a $15 \times 10 \times 10 \mathrm{~cm}$ cystic mass that contained a highly enhanced crescent portion similar to the adjacent vascular structure in its posterosuperior part. The mass

From the Department of Thoracic and Cardiovascular Surgery, ${ }^{a}$ Department of Diagnostic Radiology, ${ }^{\mathrm{b}}$ Department of Internal Medicine, and The Cardiovascular Research Institute, College of Medicine, Gyeongsang National University, Chinju, South Korea.

Received for publication Sept. 23, 1996; accepted for publication Oct. 24, 1996.

Address for reprints: Sung Ho Kim, MD, Department of Thoracic/Cardiovascular Surgery, Gyeongsang National University, College of Medicine, 660-702, Chilamdong 90, Chinju, South Korea.

J Thorac Cardiovasc Surg 1997;114:280-2

Copyright $(\mathbb{C} 1997$ by Mosby-Year Book, Inc.

$0022-5223 / 97 \$ 5.00+0 \quad \mathbf{1 2 / 5 4 / 7 8 9 2 9}$ compressed both the venae cavae and atria severely. CT of the midportion of the mass showed an abnormally dilated vascular structure emerging from the anterior aspect of the aortic root toward the mass (Fig. 1). Our impression was that the patient had an aneurysm of the RCA system, and a root angiogram was performed. The early phase of aortography revealed an abnormally enlarged artery that originated from near the RCA ostium, followed by the dense accumulation of contrast material in the posterosuperior part of the mass. The remainder of the RCA appeared normal.

The patient underwent surgery on the day of admission. The median sternotomy and the exposure of the left femoral vein were performed simultaneously. One venous cannula was inserted directly into the superior vena cava with some difficulties, and another cannula had to be inserted into the femoral vein because of severe compression of the inferior vena cava. After cardiopulmonary bypass had been initiated, the aorta was crossclamped and opened so that the internal structure of the coronary ostia could be examined. The ostium of the RCA was dilated to about $6 \mathrm{~mm}$, but there was no extracoronary ostium. The RCA was then dissected from its upper third portion toward the aorta. The abnormally dilated branch originated directly from the RCA, $5 \mathrm{~mm}$ apart from the aorta, and its diameter was about $7 \mathrm{~mm}$ (Fig. 2, left). It ran behind the superior cavoatrial junction for about $2.5 \mathrm{~cm}$, along the same course as the SA nodal artery, and blended into the aneurysm. Because the branch ran along the same course, we believe that it was a section of the SA nodal artery. After division of the dilated artery, the aneurysmal sac was opened. About $100 \mathrm{ml}$ of fresh blood was released and the remaining part of the sac was seen to be filled with well-organized thrombi (Fig. 2, right). The total weight of the thrombi was $600 \mathrm{gm}$. The aneurysmal sac was excised except for a small portion that was attached to the right 


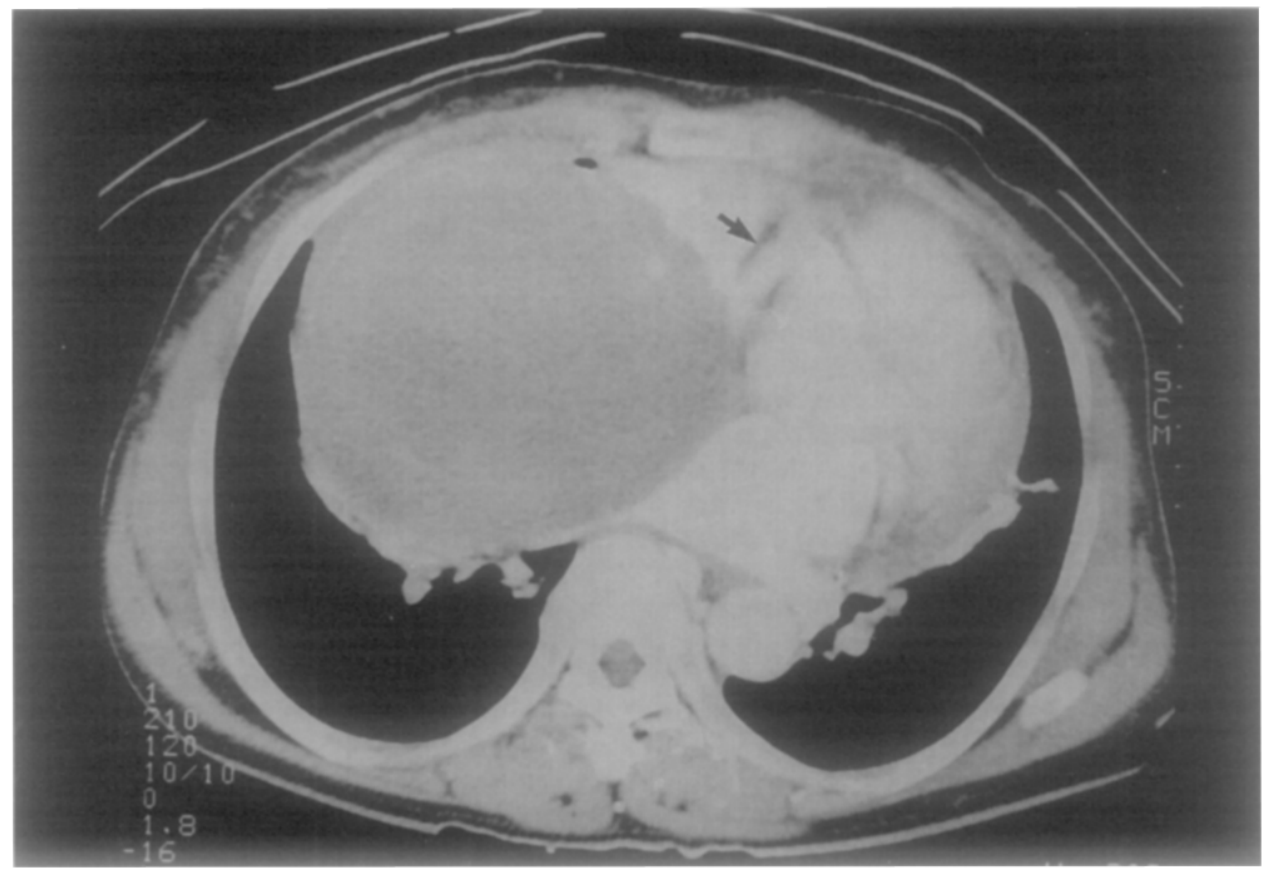

Fig. 1. CT scan of the midportion of the mass. An abnormally dilated vascular structure emerges from the anterior aspect of the aortic root in the direction of the mass (arrow).
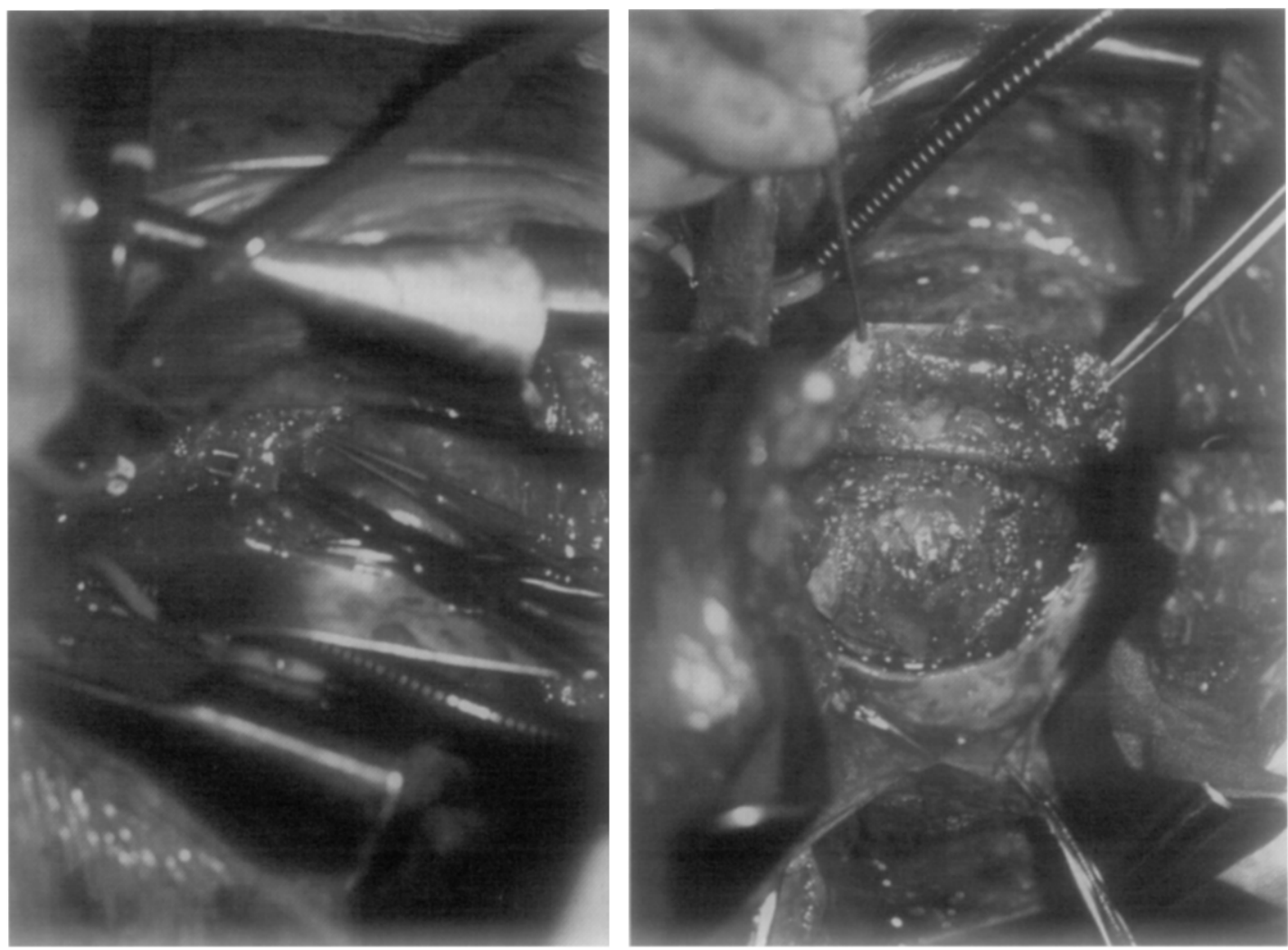

Fig. 2. Left, The right-angled clamp is hooking the abnormally dilated artery, and the forceps indicate the normal RCA. Right, Aneurysmal sac filled with organized thrombi. 
atrium. The pathologic diagnosis of the aneurysm was atherosclerotic and the follow-up CT scan showed normal atria and venae cavae. The postoperative course was uneventful and the patient was discharged on the twelfth postoperative day.

Coronary artery aneurysm is a relatively rare disease, with the incidence being reported to be $0.3 \%$ to $4.9 \%$ of patients undergoing coronary angiography. ${ }^{1}$ The most common sites of aneurysm are the proximal and middle portions of the RCA, followed by the proximal left anterior descending artery ${ }^{2}$; however, an aneurysm of the SA nodal branch of the RCA has not previously been reported. RCA aneurysm may cause angina, myocardial infarction, fistula into the cardiac chamber, and unexpected death as a result of thromboembolism or rupture. ${ }^{1,3}$ Ovrum, Froysaker, and Vatne ${ }^{4}$ reported a single case of RCA aneurysm causing superior vena caval stenosis in 1984. Our case involved both caval obstructive symptoms without any of the aforementioned clinical features.

In our case, the abnormally dilated SA nodal artery branched from the normal-sized RCA, $5 \mathrm{~mm}$ apart from the aorta. It ran behind the superior cavoatrial junction for about $2.5 \mathrm{~cm}$ and finally formed the giant aneurysm. Preoperative and postoperative electrocardiograms did not show any abnormality, and we could not confirm the SA nodal branch from the left coronary arterial system by angiography. Thus we concluded that it was indeed an aneurysm of the SA nodal artery as a result of the path it followed.

\section{REFERENCES}

1. Eid GA, Lang-Lazdunski L, Hvass U, et al. Management of giant coronary artery aneurysm with fistulization into the right atrium. Ann Thorac Surg 1993;56:372-4.

2. Swaye PS, Fisher LD, Litwin P, et al. Aneurysmal coronary artery disease. Circulation 1983;67:134.

3. Koito R, Oku T, Satoh H, et al. Right ventricular myocardial infarction and late cardiac tamponade due to right coronary artery aneurysm: a case report. Jpn J Surg 1990;20:463-7.

4. Ovrum E, Froysaker T, Vatne K. Superior caval vein stenosis due to giant aneurysm of the right coronary artery. Thorac Cardiovasc Surg 1984;32:383-5.

\section{TOTAL ANOMALOUS SYSTEMIC VENOUS DRAINAGE TO THE CORONARY SINUS IN ASSOCIATION WITH HYPOPLASTIC LEFT HEART DISEASE: MORE THAN A MERE COINCIDENCE}

Margit Kadletz, MD, ${ }^{a}$ Michael D. Black, MD, ${ }^{a}$ Jeffery Smallhorn, MD, ${ }^{\mathrm{b}}$ Robert M. Freedom, MD, ${ }^{\mathrm{b}}$ and Stella Van Praagh, MD, ${ }^{c}$ Toronto, Ontario, Canada, and Boston, Mass.

An enlarged coronary sinus receiving a persistent left superior vena cava (SVC) has been considered to accentuate the left-to-right shunt in cases of ostium secundum defects by obstructing left ventricular inflow. ${ }^{1}$ An ostium primum defect could also be considered a factor in deficient preload to the left ventricle because it represents a valveless interatrial communication that can allow bidirectional shunting at the atrial level during fetal life. Underdevelopment of the left atrium, the left ventricle, and the mitral valve, usually associated with coarctation of

From the Divisions of Cardiovascular Surgery ${ }^{\mathrm{a}}$ and Cardiology, ${ }^{\mathrm{b}}$ The Hospital for Sick Children, and The University of Toronto Faculty of Medicine, Toronto, and the Department of Pathology, Children's Hospital, Boston, Mass. ${ }^{\mathrm{c}}$

Received for publication Nov. 21, 1996; accepted for publication Dec. 23, 1996.

Address for reprints: Michael D. Black, MD, FRCSC, Division of Cardiovascular Surgery, The Hospital for Sick Children, 555 University Ave., Toronto, Canada, M5G 1X8.

J Thorac Cardiovasc Surg 1997;114:282-4

Copyright $(0) 1997$ by Mosby-Year Book, Inc.

$0022-5223 / 97 \$ 5.00+0 \quad \mathbf{1 2 / 5 4 / 8 0 0 3 4}$ the aorta, is not uncommon in patients with ostium primum defects who show signs of heart failure in early infancy. $^{2}$ Our case represents an example of coexistence of these factors that may influence the blood flow into the left ventricle during fetal life.

Clinical summary. A 3-month-old, $3.5 \mathrm{~kg}$ female infant was transferred to the Hospital for Sick Children in Toronto for a second opinion regarding further management and treatment options for a preliminary diagnosis of hypoplastic left heart syndrome. In agreement with the previous investigations, hypoplasia of the inlet, outlet, and decreased volumetrics of the left ventricle were identified. A diagnosis of hypoplastic left ventricle, however, was not made. The left ventricle was estimated to be approximately $70 \%$ normal and was found in combination with a hypoplastic "parachute" mitral valve, a partial atrioventricular septal defect (ostium primum defect), an ostium secundum atrial septal defect, a hypoplastic aorta (transverse arch) with an associated juxtaductal coarctation, and a bicuspid aortic valve. In addition, significant tricuspid valve regurgitation and a left-to-right atrial shunt were present at the time of the investigations.

Preoperative identification of an absent right SVC and a persistent left SVC was made angiographically (Fig. 1). 